Published in final edited form as:

Am Soc Clin Oncol Educ Book. 2017 ; 37: 193-204. doi:10.14694/EDBK_180328.

\title{
Adoptive T-Cell Therapy for Solid Tumors
}

\author{
Oladapo Yeku, MD, PhD, Xinghuo Li, and Renier J. Brentjens, MD, PhD \\ Department of Medicine, Memorial Sloan Kettering Cancer Center, New York, NY; Weill Cornell \\ Medicine, New York, NY; Center for Cell Engineering, and Molecular Pharmacology and \\ Chemistry Program, Memorial Sloan Kettering Cancer Center, New York, NY
}

\section{OVERVIEW}

Chimeric antigen receptor (CAR) T-cell therapy is an innovative form of immunotherapy wherein autologous $\mathrm{T}$ cells are genetically modified to express chimeric receptors encoding an antigenspecific single-chain variable fragment and various costimulatory molecules. Upon administration, these modified T cells traffic to, and recognize, cancer cells in an HLA-independent manner. CAR T-cell therapy has shown remarkable success in the treatment of CD-19-expressing B-cell acute lymphocytic leukemia. However, clinical gains to the same magnitude have not been reported in solid tumors. Several known obstacles to CAR T-cell therapy for solid tumors include target antigen identification, effective trafficking to the tumor, robust activation, proliferation, and in vivo cytotoxicity. Beyond these T-cell intrinsic properties, a complex and dynamic immunosuppressive tumor microenvironment in solid tumors hinders T-cell efficacy. Notable advancements in CAR design to include multiple costimulatory molecules, ligands, and soluble cytokines have shown promise in preclinical models, and some of these are currently in early-phase clinical trials. In this review, we discuss selected solid tumor malignancies and relevant preclinical data and highlight clinical trial results that are available. Furthermore, we outline some obstacles to CAR T-cell therapy for each tumor and propose strategies to overcome some of these limitations.

CAR T-cell therapy for solid tumor malignancies is an exciting frontier in cancer immunotherapy. The general architecture of a CAR consists of a single-chain variable fragment ( $\mathrm{scFv}$ ) derived against a predetermined tumor-associated antigen (TAA) followed by a CD3 $\zeta$ domain required for provision of signal 1 and T-cell activation upon antigen recognition. ${ }^{1}$ Upon transfection into autologous $\mathrm{T}$ cells, first-generation CAR T cells targeting HER2/Neu-expressing breast and ovarian cancer cell lines showed increased interleukin-2 (IL-2) production and cytotoxicity. ${ }^{2}$ However, it was subsequently realized that sustained activity and proliferation after receptor engagement required a secondary signal, or signal 2. ${ }^{1}$ Additional genetic modifications to include costimulatory molecules, such as $\mathrm{CD} 28^{3}$ and $4-1 \mathrm{BB},{ }^{4}$ to the $\mathrm{CD} 3 \zeta$ signaling domain led to second-generation CARs (28 $\zeta$ and $4-1 \mathrm{BB} \zeta$, respectively). Acting in concert, provision of both signal 1 and signal 2 mitigated the anergy and activation-induced cell death observed with first-generation CAR T cells. ${ }^{5}$ Direct comparison of first- and second-generation CARs directed against CD19, a TAA expressed on malignant B cells, revealed superior expansion, tumor infiltration, and

Corresponding author: Renier J. Brentjens, MD, PhD, Memorial Sloan Kettering Cancer Center, 1275 York Ave., Box 242, New York, NY 10065; brentjer@mskcc.org.

Disclosures of potential conflicts of interest provided bythe authors are available with the online article at asco.org/edbook. 
persistence in favor of the second-generation CAR design. ${ }^{6}$ Additional genetic modifications have yielded third-generation CARs composed of two distinct costimulatory domains, such as $\mathrm{CD} 28 / 4-1 \mathrm{BB} / \mathrm{CD} 3 \zeta$ or $\mathrm{CD} 28 / \mathrm{OX}-40 / \mathrm{CD} 3 \zeta$, all with varying degrees of efficacy. ${ }^{7-9}$ More recently, other approaches to optimize CAR T-cell efficacy via engineered expression of tethered or soluble ligands, cytokines, or $\mathrm{scFvs}^{10,11}$ also have been reported.

However, despite ongoing success in the management of CD19+ B-cell hematologic malignancies, progress in the solid tumor landscape has been met with many obstacles. One is the identification of suitable neoantigens or TAAs to serve as targets for CAR T-cell therapy. The biologic heterogeneity of solid tumor malignancies does not lend to an approach of one antigen fits all. This difficulty is compounded by the frequent expression of putative target antigens on normal tissues that leads to on-target, off-tumor toxicity. ${ }^{12}$ Despite this, acceptable antigens, such as EGFR variant III (EGFRIII), ${ }^{13} \mathrm{GD} 2,{ }^{14}$ mucin 1 (MUC-1), ${ }^{9}$ mucin 16 (MUC-16), ${ }^{15}$ carcinoem-bryonicantigen, ${ }^{16}$ mesothelin, $,{ }^{17} \mathrm{CA}-\mathrm{IX},{ }^{18}$ and prostate-specific membrane antigen (PSMA) ${ }^{19}$ have been characterized and are in various stages of clinical development (Table 1). Besides identification of a suitable TAA, trafficking of administered CAR T cells to the tumor is another challenge to effective therapy. Consequently, experimental models to improve innate CAR T-cell trafficking via coexpression of chemokine receptors ${ }^{20}$ and compartmental/intercavitary administration of CAR T cells are being investigated. ${ }^{21}$ Perhaps the most notable limitation lies in the dynamic, complex, and often inhibitory tumor microenvironment present in many solid tumor malignancies. For instance, myeloid-derived suppressor cells and tumor-associated macrophages (TAMs) decrease local tryptophan levels in the tumor microenvironment, ${ }^{22}$ depriving CAR T cells of an essential amino acid necessary for optimal function. In addition, regulatory $\mathrm{T}$ cells, myeloid-derived suppressor cells, and TAMs elaborate inhibitory cytokines such as IL-4, IL-10, leukemia inhibitor factor, and transforming growth factor $\beta$-all of which further repress T-cell function. ${ }^{23-25}$ Strategies aimed at overcoming these limitations are currently areas of intense investigation.

\section{GLIOBLASTOMA}

IL-13 receptor a 2 (IL-13Ra2) and EGFRIII are two major targets that have been investigated for CAR T-cell therapy against glioblastoma. IL-13Ra 2 is overexpressed in more than $50 \%$ of glioblastomas, but limited expression on normal brain tissue is retained. ${ }^{34}$ Importantly, IL-13Ra 2 expression has been reported on both stem-like and more differentiated malignant cells, making it a favorable target with the potential to eliminate tumor-initiating cells and prevent tumor recurrence. Kahlon et $\mathrm{al}^{35}$ generated a firstgeneration IL-13Ra2-specific CAR that redirected human CD8+ cytotoxic T lymphocytes to eradicate established glioblastoma tumor in an orthotopic xenograft model. In a separate study, IL-13Ra2-specific CAR T cells targeted glioma stem-like cancer-initiating cells and abrogated their tumor-initiating activity in mice. ${ }^{36} \mathrm{~A}$ phase I trial was conducted in three patients with recurrent glioblastoma who received repetitive intracranial infusions of firstgeneration IL-13Ra2-specific CAR T cells without nonmyeloablative preconditioning. ${ }^{26}$ Only transient antiglioma responses were observed in two patients. The unsatisfactory response may be explained by poor expansion and persistence of CAR T cells in vivo, because the trial used first-generation CAR T cells. As previously mentioned, first- 
generation CAR T cells show diminished expansion upon repeated antigen stimulation. ${ }^{37} \mathrm{In}$ a recent case report, a patient showed tumor regression after multiple intracranial infusions of second-generation IL-13Ra2-specific CAR T cells. ${ }^{38}$ Interestingly, CAR T cells with intracavitary administration prevented only local tumor recurrence but failed to control tumor progression at distant sites. In contrast, intraventricular infusions resulted in tumor regression in all intracranial and spinal tumors. EGFRIII is a tumor-specific, mutated form of wild-type EGFR and is commonly expressed in glioblastoma. Because of an absence in normal tissues, EGFRIII is ideally suited to minimize on-target, off-tumor toxicity. Multiple preclinical studies demonstrate that EGFRIII-specific CAR T cells recognize and eliminate antigen-positive glioblastoma tumors in vitro and in vivo without cross-reacting with wildtype receptors present on normal tissues. ${ }^{1339-41}$

\section{NEUROBLASTOMA}

In contrast to glioblastoma, neuroblastoma originates from immature neurons and mostly occurs in infants and young children. Multiple targets, including GD2 and CD171, have been identified and tested for development of CAR T-cell therapy. GD2 is expressed on tumors of neuroectodermal origin, including neuroblastoma and melanoma. ${ }^{42}$ In a preclinical study, GD2-specific CAR T cells exhibited potent cytotoxicity and cytokine production in response to antigen stimulation. ${ }^{43} \mathrm{~A}$ phase I clinical trial by Louis et $\mathrm{al}^{27}$ reported a complete remission rate of $27 \%$ (three of 11 patients) in patients treated with firstgeneration GD2-specifc CAR T cells without lymphodepletion. Furthermore, CAR T-cell persistence was observed for up to 192 weeks in this study. ${ }^{27} \mathrm{CD} 171$ is a surface antigen expressed on many types of cancer, including neuroblastoma. Functionally, CD171 has been reported to enhance tumor cell activity. ${ }^{44}$ The first CD171-specifc CAR was developed by Gonzalez et al, ${ }^{45}$ and the engineered $\mathrm{T}$ cells displayed robust antitumor activity in vitro. However, subsequent treatment with first-generation GD2-targeting CD8+ lymphocytes in clinical trials failed to control disease progression, and CAR T-cell persistence was inversely correlated with disease burden. ${ }^{28}$ The authors speculated that the minimal antitumor response was due in part to the lack of coadministration of IL-2, which is especially critical to support the function of first-generation CARs. It is also worthwhile to note that absence of a CD4+ subset in transferred T cells may have compromised function and persistence; emerging data indicate that optimal CAR T-cell efficacy requires both CD4+ and CD8+ compartments. ${ }^{46}$

\section{Prospects}

Efficient CAR T-cell trafficking and localization to the tumor site are prerequisites for optimal antitumor efficacy. This is especially challenging for neuro-oncological malignancies such as glioblastoma because of limited T-cell infiltration in brain. CAR T cells modified to express chemokine receptors, such as chemokine receptor 2 , have shown improved trafficking and tissue homing in a neuroblastoma model. ${ }^{47}$ An alternative strategy is to target the tumor vasculature. Local delivery of tumor necrosis factor a (TNF-a) has been reported to upregulate the expression of adhesion molecules, such as vascular cell adhesion protein 1 and intracellular adhesion molecule 2 on endothelial cells, and to enhance T-cell infiltration. ${ }^{48}$ Therefore, genetically modifying CAR T cells to secrete TNF-a is one 
potential approach to overcome this limitation and improve CAR T-cell efficacy. Combining CAR T cells with lenalidomide has been reported to enhance the formation of immune synapses and improve persistency of CAR T cells in vivo, ${ }^{49}$ providing a rationale for combinatorial approaches for CAR T-cell therapy.

\section{HEAD AND NECK CANCER}

A target of particular interest is the ErbB receptor family, which contains four members, designated EGFR (or ErbB-1), ErbB-2 (HER2 or neu), ErbB-3, and ErbB-4. ${ }^{50}$ ErbB receptors are transmembrane tyrosine kinase proteins that promote cell growth and inhibit apoptosis. Overexpression of these receptors, especially ErbB1 and ErbB2, have been observed in many malignancies, such as head and neck, breast, and lung cancers. ${ }^{51-53}$ ErbB receptors can exist either in homodimeric or heterodimeric configurations, ${ }^{54}$ and it has recently been appreciated that the transforming potential of the heterodimeric configuration is superior. ${ }^{55}$ In addition, targeting individual ErbB receptors often results in acquired resistance because of enhanced activity of nontargeted receptors. In light of this, Davies et $\mathrm{al}^{56}$ developed a second-generation CAR that incorporates a chimeric polypeptide, TIE, designed to achieve broad specificity for the ErbB network. ErbB-specific CAR T cells recognized and lysed several ErbB-positive tumor cell lines in vitro. These cell lines showed expression of a broad range of receptor combinations. In SCID-beige mice, CAR T-cell administration led to the eradication of established xenografts derived from ErbB1/2overexpressing and ErbB2/3-overexpressing tumors. All four ErbB receptors are widely expressed in normal tissues, albeit at lower levels, which could lead to on-target, off-tumor toxicity. Van der Stegen et al ${ }^{57}$ examined treatment toxicity in SCID-beige mice after delivery of the ErbB-specific CAR T cells via different routes. Compared with the intraperitoneal route, intratumoral delivery promoted tumor regression without eliciting any cytokine release syndrome. Consideration of intratumoral delivery has been proposed in clinical trials. ${ }^{58}$

\section{Prospects}

Multiple mechanisms have been exploited by cells in head and neck squamous cell carcinoma to escape immune surveillance. Data suggest that 55\% to $65 \%$ of head and neck squamous cell carcinomas express PD-L1, which binds to its cognate receptor PD-1 on T cells, and suppress immune responses. ${ }^{59}$ The presence of infiltrating regulatory $\mathrm{T}$ cells also contributes to the immunosuppressive tumor microenvironment via secretion of IL-10 and transforming growth factor $\beta$ and via direct inhibition of T cells. ${ }^{60}$ Therefore, strategies to optimize T-cell efficacy for head and neck squamous cell carcinoma could involve rational combinations of anti-PD-1/PD-L1 antibody with CAR T cells or armored CAR T cells modified to secrete blocking PD-1/PD-L1 scFvs.

\section{BREAST CANCER}

HER2 and mesothelin are two TAAs currently under investigation. Amplification of HER2 oncogene leads to uncontrolled cell proliferation and occurs in approximately $20 \%$ of breast cancers. ${ }^{61}$ Globerson-Levin et al ${ }^{62}$ generated a HER2-specific, second-generation CAR containing CD28 and fragment crystallizable receptor (FcyR) signaling domains and tested 
its efficacy in a syngeneic mouse mammary tumor model. Transduced $\mathrm{T}$ cells exhibited potent cytotoxic capacity and cytokine secretion upon antigen recognition. ${ }^{62}$ In addition, repeated injections of HER2-directed CAR T cells eliminated spontaneous HER2-positive tumors and enhanced survival in transgenic mice. Mesothelin is a glycoprotein expressed on a broad range of solid tumors, with limited expression on normal tissues. ${ }^{63}$ Mesothelin expression has been shown to be enriched in triple-negative breast cancer and is associated with poor outcomes. ${ }^{64}$ Patients with triple-negative breast cancer are not suitable for targeted therapy or hormone therapy, so adoptive transfer of mesothelin-specific CAR T cells offers an alternative option. Tchou et al ${ }^{65}$ engineered mesothelin-specific CAR T cells and reported a cytolytic capacity against primary breast tumor cells in vitro. However, in vivo antitumor activity was not evaluated in this study.

\section{Prospects}

A major therapeutic challenge to therapy in breast cancer is acquired resistance that results from antigen escape. For instance, under selective pressure, HER2 can undergo proteolysis to cleave the extracellular domain without compromising kinase activity. One approach to overcome this limitation is to use a dual-targeting CAR system, in which engineered $\mathrm{T}$ cells coexpress two CARs that recognize two distinct antigens. Redirected $\mathrm{T}$ cells can be activated in the presence of either antigen, in essence creating an or-switch, to mitigate antigen-loss escape. ${ }^{66}$ Alternatively, CAR T cells can be modified to secrete inflammatory cytokines, such as IL-12, or costimulatory ligands, such as 4-1BB ligand, to stimulate an endogenous immune response against tumor cells via epitope spreading. ${ }^{6768}$

\section{NON-SMALL CELL LUNG CANCER}

Overexpression of EGFR is commonly seen in patients with non-small cell lung cancer, and small molecules inhibiting EGFR kinase activity have shown therapeutic benefits. Feng et $\mathrm{al}^{29}$ reported efficacy of second-generation EGFR-specific CAR T cells that incorporate CD137 and CD3 $\zeta$ signaling domains. In vitro antitumor efficacy was demonstrated via potent cytotoxicity and by interferon $\gamma$ (IFN- $\gamma$ ) and IL-2 secretion in response to EGFRpositive lung carcinoma cells. In a phase I clinical study, two of 11 patients with refractory non-small cell lung cancer experienced a partial response after treatment with secondgeneration EGFR-specific CAR T cells after lymphodepletion. CAR T cells were detected in the peripheral blood of treated patients along with detection of CAR T cells at tumor sites, and eradication of EGFR-positive tumor cells was noted in post-treatment biopsies. ${ }^{29}$ Mesothelin and carcinoembryonic antigen are also two attractive targets because of their elevated expressions in non-small cell lung cancer. ${ }^{69,70}$ Multiple preclinical studies have reported antitumor efficacy of mesothelin- and carcinoembryonic antigen-specific CAR T cells against antigen-positive tumors, such as ovarian and liver cancers. However, direct evidence of antitumor efficacy against primary tumor samples or lung cancer cell lines has not been evaluated. ${ }^{71-74}$

\section{MESOTHELIOMA}

In addition to breast and lung cancer, mesothelin is overexpressed on the majority of mesotheliomas. Carpenito et al ${ }^{71}$ engineered several mesothelin-specific CARs that used 
different combinations of costimulatory domains and compared their antitumor efficacy.

Despite equivalent cytotoxicity in vitro, third-generation CARs, which contained CD137 and CD28 costimulatory domains in tandem, showed marginally superior tumor rejection in a subcutaneous mesothelioma tumor model compared with second-generation CARs that had either costimulatory domain alone. In a separate study, a fully humanized second-generation anti-mesothelin CAR mediated tumor elimination in vitro and in vivo. ${ }^{72}$ Importantly, CAR T-cell activation was not subverted by soluble tumor-secreted or recombinant mesothelin. This mitigates the concern that CAR T cells could be blocked or preoccupied by the soluble portion of mesothelin detected in some patients. In addition to CAR development, identifying an optimal route of administration has been explored. Using an orthotopic mesothelioma xenograft model, Adusumilli et al ${ }^{73}$ showed that intrapleural delivery of second-generation mesothelin-directed CAR T cells vastly outperformed intravenous delivery, requiring 30 -fold fewer CAR T cells to induce tumor eradication. In a phase I clinical trial, four patients with advanced mesothelioma or pancreatic cancer were treated with repetitive intravenous infusions of second-generation mesothelin-specific CART cells. Moderate antitumor responses were observed, and CAR T cell persistence and trafficking to the tumor site were detected. Interestingly, this study also reported induction of an antitumor humoral immune response after CAR T-cell therapy, evidenced by an elevated antibody response to a variety of tumor-associated proteins. This observation highlights the potential of CAR T-cell therapy to elicit a systemic immune response targeted to a broader range of antigens mediated via epitope spreading. ${ }^{17}$ One patient experienced anaphylaxis and cardiac arrest after the third infusion on this trial, and this adverse event was believed to be associated with the development of antibodies against the murine-derived scFv. ${ }^{75}$

\section{Prospects}

Like many other solid tumors, lung cancer and mesothelioma possess an immunosuppressive microenvironment. Overexpression of inhibitory molecules, such as PD-L1 and indoleamine 2,3-dioxygenase (IDO) by tumor cells and myeloid-derived suppressor cells have been reported in patients with non-small cell lung cancer or mesothelioma. ${ }^{76-78}$ Multiple strategies, including additional modification of CAR T cells and combinatorial approaches, can be adopted to overcome these obstacles and enhance CAR T-cell efficacy. For instance, CAR T cells can be engineered to express dominant negative PD-1 receptors ${ }^{79}$ or antiPD-1/PD-L1 agents to promote resistance to such inhibition. ${ }^{11}$ In addition, rational combinations with PD-1/PD-L1 blockade antibody or IDO inhibitors may restore CAR Tcell activity.

\section{OVARIAN CANCER}

Several antigens have been exploited as targets for CAR T-cell therapy in ovarian cancer. Barber et al ${ }^{80}$ engineered a first-generation NKG2D receptor CAR that recognizes the cognate NKG2D ligand expressed on ovarian cancer cell lines and patient-derived primary ovarian cancer samples. In both cell lines and primary samples, these CAR T cells were activated, secreted proinflammatory cytokines, and lysed tumor cells in an NKG2Ddependent fashion. In vitro efficacy and repression of flank-implanted ovarian cancer cells in a xenogeneic model using HER2/neu-directed second-generation CAR T cells also have 
been reported. ${ }^{81}$ The Lewis- $\mathrm{Y}\left(\mathrm{Le}^{\mathrm{Y}+}\right)$ antigen is a carbohydrate molecule that has been shown to be overexpressed on $70 \%$ of epithelial-derived tumors. ${ }^{82-84}$ Westwood et al ${ }^{85}$ designed a CD28C second-generation CAR directed against $\mathrm{Le}^{\mathrm{Y}}+$ tumors, one of which included ovarian cancer in an OVCAR-3 tumor model. These CAR T cells showed significantly enhanced IFN- $\gamma$ production, proliferation, and cytotoxicity when exposed to $\mathrm{Le}^{\mathrm{Y}+}$ OVCAR-3 cells. ${ }^{85}$ Furthermore, treatment with $\mathrm{Le}^{\mathrm{Y}{ }^{+} \text {-specific CARs inhibited growth }}$ of flank-implanted OVCAR-3 in immunodeficient NOD-SCID mice. Another TAA under development is MUC-16. MUC-16 is a membrane-associated molecule that belongs to the mucin family of glycoproteins. ${ }^{86}$ The extracellular domain of MUC-16 is cleaved into a soluble antigen (cancer antigen 125 [CA-125]), leaving a retained portion (MUC-16-CD) that can be targeted by adoptively transferred engineered $\mathrm{T}$ cells. ${ }^{15}$ Chekmasova et al ${ }^{15}$ engineered a second-generation (CD285 MUC-16-CD-directed CAR that showed efficacy against OVCAR-3 and patient-derived tumor samples. Armored CAR T-cells which have been engineered to secrete IL-12 directed against MUC-16-CD have been shown to be superior in vitro and in vivo to second-generation MUC-16-CD-directed CARs. ${ }^{87}$ Similarly, mesothelin, a glycoprotein molecule expressed on pleural, pericardial, and peritoneal cells ${ }^{88}$ has been explored as a TAA in ovarian cancer. Carpenito et $\mathrm{al}^{71}$ reported notable in vitro cytotoxicity using mesothelin-directed third-generation (CD28/4-1BB $\zeta$ CAR T cells. Folate receptor $\mathrm{a}(\mathrm{FRa})$ is a cell surface-anchored glycosylphosphatidylinositol molecule ${ }^{89}$ that is highly expressed on ovarian cancer cells, ${ }^{90}$ and it has been shown to be predictive of negative outcomes in patients with ovarian cancer. ${ }^{91}$ On the basis of the preclinical efficacy of folate receptor-directed CAR T cells, ${ }^{92}$ Kershaw et al ${ }^{32}$ conducted a phase I clinical trial using first-generation FR-positive-specific CAR T cells with or without exogenous IL-2 in patients with relapsed/refractory epithelial ovarian cancer. All 14 patients treated in this study had progressive disease. There was no reported decline in CA-125 or antitumor response. ${ }^{32}$ In one of the cohorts in this study, the adoptively transferred cells were labeled with indium-111 to facilitate in vivo imaging. After intravenous administration, most of the labeled $\mathrm{T}$ cells persisted in the lungs, without any evidence of specific localization to the tumor sites. This finding partially explained the decreased systemic persistence and lack of efficacy in this trial.

\section{Prospects}

The inhibitory tumor microenvironment in ovarian cancer, including the highly suppressive ascitic microenvironment, ${ }^{93}$ is an important obstacle that needs to be addressed for CAR T cells to be successful in this disease. One approach is to armor the CAR T cells with soluble cytokines, such as IL-12, ${ }^{21}$ a proinflammatory cytokine that has been shown to enhance the cytotoxic capability of effector T cells ${ }^{94}$ and to reprogram dendritic cells and myeloidderived suppressor cells. ${ }^{95}$ Potential combinations of checkpoint blockade with secondgeneration or armored CAR T cells also could be explored as a means to augment CAR Tcell efficacy via recruitment of endogenous effector T cells. ${ }^{96,97}$

\section{PROSTATE CANCER}

Prostate stem-cell antigen and PSMA are two of the most commonly used target antigens for CAR T-cell therapy for prostate cancer. Predominantly found on prostate tissue, prostate 
stem-cell antigen is a glycosylphosphatidylinositol-anchored antigen located on the cell surface. ${ }^{98}$ In contrast, PSMA is a type II transmembrane protein that reportedly is present at low levels on the cytosolic/apical surface of normal prostate tissue. ${ }^{99}$ However, during malignant transformation to prostate adenocarcinoma, it translocates to the extracellular/ luminal side of the epithelium. ${ }^{100}$ Zhong et $\mathrm{al}^{8}$ generated a PSMA-directed third-generation CAR by engineering the $4-1 \mathrm{BB}$ receptor costimulatory molecule in tandem with CD28 and $\mathrm{CD} 3 \zeta$ (named $\mathrm{P} 28 \mathrm{BB} \zeta$ ) and tested its efficacy against a human prostate cancer cell line in an SCID/beige mouse model. These CAR T cells showed robust proliferation and cytotoxicity in vitro. In tumor-bearing mice, treatment with $\mathrm{P} 28 \mathrm{BB} \zeta$ greatly enhanced survival compared with control mice. Mechanistically, these T cells showed increased intracellular signaling and enhanced production of granzyme, IFN- $\gamma$, TNF- $a$, and granulocyte-macrophage colony-stimulating factor. Hillerdal et al ${ }^{101}$ also have reported efficacy of a prostate stem-cell antigen-directed third-generation CAR that uses CD28 and OX-40 costimulatory molecules. In addition to robust proliferation, cytokine production, degranulation, and cytotoxicity upon recognition of prostate stem-cell antigen-expressing cells, these CAR T cells also were able to significantly delay subcutaneous tumor growth and prolong survival in nude mice. A phase I clinical trial by Junghans et al ${ }^{102}$ reported a response rate, by prostate-specific antigen level, of $40 \%$ (two of five patients) with a firstgeneration PSMA-directed CAR after non-myeloablative preconditioning and concurrent IL-2 administration. In another phase I report, Slovin et $\mathrm{al}^{30}$ reported tolerability and systemic persistence of up to 2 weeks with second-generation PSMA-directed CART cells.

\section{Prospects}

TAMs have been implicated in prostate cancer. ${ }^{103}$ Specifically, TAMs are recruited to and infiltrate the tumor stroma in a colony stimulating factor-1 (CSF-1)/CSF-1 receptor (CSF-1R) -dependent fashion, ${ }^{104}$ where it has been shown to promote tumor and vascular growth ${ }^{105}$ and to mediate resistance to hormonal therapy. ${ }^{106}$ In experimental models, clodronate-mediated depletion of TAMs led to notable inhibition of tumor growth. ${ }^{105}$ One approach to optimize CAR T-cell therapy for prostate cancer might involve preconditioning therapy with either pharmacologic (AZD6495) or antibody-mediated (anti-CSF-1R) depletion of TAMs before CAR T-cell administration. Alternatively, second-generation CAR $\mathrm{T}$ cells can be armored via additional genetic modifications to secrete soluble CSF-1R inhibitors.

\section{RENAL CELL CARCINOMA}

Carboxy-anhydrase-IX (CA-IX) expression in metastatic renal cell carcinoma has been exploited as a target for adoptive transfer of engineered T cells. ${ }^{18} \mathrm{CA}-\mathrm{IX}$ is a metalloprotease that reversibly catalyzes the hydration of carbon dioxide. ${ }^{107}$ Although it is useful as a TAA in renal cell carcinoma, it also is expressed on several normal tissues, such as the gastric mucosa epithelium, small intestine epithelium, duodenum, and biliary tree. ${ }^{108}$ In addition, expression of CA-IX is inducible in many other tissues under hypoxic conditions. ${ }^{109}$ In preclinical studies, Weijtens et al ${ }^{110}$ showed robust cytokine production and cytotoxic activity of first-generation CA-IX-directed engineered $\mathrm{T}$ cells against renal carcinoma cells. Lamers at al ${ }^{31}$ initially treated three patients with CA-IX-positive 
metastatic clear cell renal cell carcinoma with first-generation CA-IX-specific CAR T cells and exogenous IL-2 administration without nonmyeloablative preconditioning. Two of these patients developed grade 2 to 4 liver enzyme toxicity, and liver biopsies showed cholangitis that involved T-cell infiltration around bile ducts and confirmation of CA-IX expression on the biliary ductal epithelium. Furthermore, all three patients developed antibodies against the murine-derived scFv. To abrogate any more toxicity, the investigators pre-administered unmodified antibody from which the scFv was derived (cG250) to saturate and protect the liver before CAR T cell administration. With this amended approach, Lamers et al ${ }^{18}$ successfully eliminated treatment-associated hepatoxicity in all four patients who received antibody pretreatment. Curiously, they were unable to detect any human anti-mouse antibodies against the cellular product in patients who underwent antibody pretreatment, which suggests that perhaps the nonspecific inflammation caused by the cholangitis contributed to the generation of human anti-mouse antibodies. Despite CAR T-cell persistence of 3 to 5 weeks, there were no clinical responses. ${ }^{18}$

\section{Prospects}

Myeloid-derived suppressor cells ${ }^{111,112}$ have been shown to facilitate T-cell suppression via arginase-mediated down-regulation of the T-cell receptor $\zeta$ chain. ${ }^{113}$ Increased levels of circulating regulatory $\mathrm{T}$ cells also have been reported in patients with renal cell carcinoma ${ }^{114}$ and are inversely corelated with survival. ${ }^{115}$ Sunitinib is a U.S. Food and Drug Administration-approved multikinase inhibitor for the treatment of metastatic renal cell carcinoma, and it has been shown to decrease myeloid-derived suppressor cells, ${ }^{116}$ enhance type-I IFN responses, and decrease regulatory $\mathrm{T}$ cells function in patients with renal cell carcinoma. ${ }^{117}$ Could sunitinib be used as preconditioning and maintenance therapy after CAR T-cell administration? This hypothesis could readily be subject to testing with a second-generation or armored CARs in a syngeneic model of metastatic renal cell carcinoma. ${ }^{118}$

\section{SARCOMA}

Although sarcomas represent a heterogeneous group of mesenchymal-derived neoplasms, there has been some success in identifying TAAs that are expressed across different sarcoma subtypes. Ahmed et al ${ }^{119}$ exploited the expression of HER2 on osteosarcomas by engineering a second-generation HER2-directed CAR construct. These HER2-specific T cells showed robust cytokine production, proliferation, and cytotoxicity in vivo. Adoptive transfer of these genetically modified $\mathrm{T}$ cells effectively treated both localized and metastatic osteosarcoma in SCID mice. Second-generation (CD28S NKG2D ligand-directed CAR T cells also have shown efficacy in preclinical in vitro models of Ewing sarcoma. ${ }^{120}$ Another approach reported by Huang et al ${ }^{121}$ involved generation of an anti-IL-11 receptor a chain (IL-11Ra) second-generation CAR. IL-11Ra expression has been reported on multiple tumor types, including osteosarcoma, ${ }^{122}$ prostate cancer, ${ }^{123}$ and breast cancer. ${ }^{124}$ Signaling via the IL-11/IL-11Ra pathway has been shown, among many other things, to promote osteoclastogenesis. ${ }^{125,126} \mathrm{IL}-11 \mathrm{Ra}$-specific CAR T cells were effective against both primary tumors and pulmonary metastasis in a nude mouse model of osteosarcoma. ${ }^{121}$ In a phase I/II trial by Ahmed et al, ${ }^{33} 19$ patients with HER2-positive sarcoma were treated with 
second-generation HER2-specific CAR T cells without nonmyeloablative preconditioning. Adoptively transferred cells were detectable for up to 9 months in a fraction of treated patients. Furthermore, in patients who underwent metastatectomy 9 to 15 weeks after CAR T-cell therapy, HER2-specific CAR T cells were detected in the tumor samples by qualitative polymerase chain reaction. ${ }^{33}$ Of the 17 evaluable patients, four had stable disease for as long as 12 weeks to 14 months. Three patients who underwent metastatectomy after CAR T-cell therapy remained in remission for up to 16 months.

\section{Prospects}

The importance of angiogenesis and vascular invasion in sarcoma has been well described. ${ }^{127}$ In addition, the presence of M2-polarized TAMs has been reported, and these cells also could contribute to pathologic vasculogenesis via VEGF production. ${ }^{128}$ Could CAR T cells be additionally modified to secrete soluble VEGF inhibitors? Perhaps they could be used in combination with anti-VEGF antibodies or multikinase inhibitors like pazopanib or sunitinib? Preconditioning or combination with immune-modifying agents, such as trabectedin ${ }^{129}$ or mifamuritide, which act against monocytes/macrophages, could be explored as a means to optimize CAR T-cell efficacy for this disease.

\section{CONCLUSION}

Despite enthusiasm for adoptive immunotherapy, many obstacles must be addressed before CAR T-cell therapy joins the armamentarium for management of solid tumors. In tumor types that have more than one TAA, there is the question of which is the optimal target to minimize tumor escape via antigen loss/downregulation. When more than one TAA is expressed, could scFvs against both antigens be engineered in an or-activation or andactivation configuration to combat tumor heterogenicity or to improve safety, respectively? The prerequisite for nonmyeloablative preconditioning also must be rigorously assessed in syngeneic solid tumor models and clinical trials. There might be a hypothetical benefit to remodeling the endogenous lymphoid populations in anticipation of activation/recruitment by specifically armored CAR T cells, but this remains to be tested. Appropriate preclinical models and mechanisms of efficacy and resistance to CAR T-cell therapy also should be explored, ideally before clinical development. Driven mostly by the importance of demonstrating antitumor efficacy against human cancer cell lines, the clear majority of preclinical CAR T cell validation experiments have been in the context of SCID/beige or other immunodeficient tumor models. These models potentially could underestimate the immunomodulatory effect of the endogenous immune systems of the hosts and the effects of the immunosuppressive tumor microenvironment on adoptively transferred $\mathrm{T}$ cells. Consequently, more effort is being directed at understanding the interaction of the tumor microenvironment and the endogenous immune system in immunocompetent mouse models in addition to the prerequisite xenogeneic research. The route of CAR T-cell administration also could be tailored to each solid tumor malignancy according to what is known about each tumor's biology. For example, clinical trials of intrapleural and intraperitoneal administration of CAR T cells for mesothelioma and ovarian cancer, respectively, are in progress. Lingering issues with toxicities in the form of cytokine release syndrome, neurotoxicity, and off-tumor cytotoxicity also are being investigated. Ultimately, knowledge 
of how best to mitigate these toxicities, coupled with rational combinations of chemotherapy, surgery, radiotherapy, or immunomodulators, will pave the way for the next breakthroughs in CAR T-cell therapy for solid tumor malignancies.

\section{Acknowledgments}

Oladapo Yeku and Xinghuo Li contributed equally to this article. This work was funded in part by the following: National Institutes of Health Grants No. R01CA138738-05, PO1CA059350, PO1CA190174-01; the Ovarian Cancer Research Fund Grant No. 327501; Memorial Sloan Kettering T32 Investigational Therapeutics Training Program Grant No. T32-CA009207; the annual Terry Fox Run for Cancer Research in New York, NY, Grant No. 29410; Kate's Team; Carson Family Charitable Trust Grant No. 10171; William Lawrence and Blanche Hughes Foundation Grant No. 10251; Emerald Foundation Grant No. 11625; and the Experimental Therapeutics Center of Memorial Sloan Kettering Cancer Center Grant No. 13072.

\section{References}

1. Sadelain M, Brentjens R, Rivière I. The basic principles of chimeric antigen receptor design. Cancer Discov. 2013; 3:388-398. [PubMed: 23550147]

2. Stancovski I, Schindler DG, Waks T, et al. Targetingof T lymphocytes to Neu/HER2-expressing cells using chimeric single chain Fv receptors. J Immunol. 1993; 151:6577-6582. [PubMed: 7902379]

3. Brentjens RJ, Santos E, Nikhamin Y, et al. Genetically targeted T cells eradicate systemic acute lymphoblastic leukemia xenografts. Clin Cancer Res. 2007; 13:5426-5435. [PubMed: 17855649]

4. Kalos M, Levine BL, Porter DL, et al. T cells with chimeric antigen receptors have potent antitumor effects and can establish memory in patients with advanced leukemia. Sci Transl Med. 2011; 3:95ra73.

5. Chambers CA, Allison JP. Co-stimulation in T cell responses. Curr Opin Immunol. 1997; 9:396404. [PubMed: 9203422]

6. Savoldo B, Ramos CA, Liu E, et al. CD28 costimulation improves expansion and persistence of chimeric antigen receptor-modified T cells in lymphoma patients. J Clin Invest. 2011; 121:18221826. [PubMed: 21540550]

7. Zhao Y, Wang QJ, Yang S, et al. A herceptin-based chimeric antigen receptor with modified signaling domains leads to enhanced survival of transduced T lymphocytes and antitumor activity. J Immunol. 2009; 183:5563-5574. [PubMed: 19843940]

8. Zhong XS, Matsushita M, Plotkin J, et al. Chimeric antigen receptors combining 4-1BB and CD28 signaling domains augment PI3kinase/AKT/Bcl-XL activation and CD8* T cell-mediated tumor eradication. Mol Ther. 2010; 18:413-420. [PubMed: 19773745]

9. Wilkie S, Picco G, Foster J, et al. Retargeting of human T cells to tumor-associated MUC1: the evolution of a chimeric antigen receptor. J Immunol. 2008; 180:4901-4909. [PubMed: 18354214]

10. Yeku OO, Brentjens RJ. Armored CAR T-cells: utilizing cytokines and pro-inflammatory ligands to enhance CAR T-cell anti-tumour efficacy. Biochem Soc Trans. 2016; 44:412-418. [PubMed: 27068948]

11. Suarez ER, Chang K, Sun J, et al. Chimeric antigen receptor T cells secreting anti-PD-L1 antibodies more effectively regress renal cell carcinoma in a humanized mouse model. Oncotarget. 2016; 7:34341-34355. [PubMed: 27145284]

12. Morgan RA, Yang JC, Kitano M, et al. Case report of a serious adverse event following the administration of $\mathrm{T}$ cells transduced with a chimeric antigen receptor recognizing ERBB2. Mol Ther. 2010; 18:843-851. [PubMed: 20179677]

13. Johnson LA, Scholler J, Ohkuri T, et al. Rational development and characterization of humanized anti-EGFR variant III chimeric antigen receptor T cells for glioblastoma. Sci Transl Med. 2015; 7:275ra22.

14. Prapa M, Caldrer S, Spano C, et al. A novel anti-GD2/4-1BB chimeric antigen receptor triggers neuroblastoma cell killing. Oncotarget. 2015; 6:24884-24894. [PubMed: 26298772] 
15. Chekmasova AA, Rao TD, Nikhamin Y, et al. Successful eradication of established peritoneal ovarian tumors in SCID-beige mice following adoptive transfer of T cells genetically targeted to the MUC16 antigen. Clin Cancer Res. 2010; 16:3594-3606. [PubMed: 20628030]

16. Chmielewski M, Hahn O, Rappl G, et al. T cells that target carcinoembryonic antigen eradicate orthotopic pancreatic carcinomas without inducing autoimmune colitis in mice. Gastroenterology. 2012; 143:1095-1107. e2. [PubMed: 22750462]

17. Beatty GL, Haas AR, Maus MV, et al. Mesothelin-specific chimeric antigen receptor mRNAengineered T cells induce anti-tumor activity in solid malignancies. Cancer Immunol Res. 2014; 2:112-120. [PubMed: 24579088]

18. Lamers CH, Sleijfer S, van Steenbergen S, et al. Treatment of metastatic renal cell carcinoma with CAIX CAR-engineered T cells: clinical evaluation and management of on-target toxicity. Mol Ther. 2013; 21:904-912. [PubMed: 23423337]

19. Zuccolotto G, Fracasso G, Merlo A, et al. PSMA-specific CAR-engineered T cells eradicate disseminated prostate cancer in preclinical models. PLoS One. 2014; 9:e109427. [PubMed: 25279468]

20. Moon EK, Carpenito C, Sun J, et al. Expression of a functional CCR2 receptor enhances tumor localization and tumor eradication by retargeted human $\mathrm{T}$ cells expressing a mesothelin-specific chimeric antibody receptor. Clin Cancer Res. 2011; 17:4719-4730. [PubMed: 21610146]

21. Koneru M, O'Cearbhaill R, Pendharkar S, et al. A phase I clinical trial of adoptive T cell therapy using IL-12 secreting MUC-16(ecto) directed chimeric antigen receptors for recurrent ovarian cancer. J Transl Med. 2015; 13:102. [PubMed: 25890361]

22. Ninomiya S, Narala N, Huye L, et al. Tumor indoleamine 2,3-dioxygenase (IDO) inhibits CD19CART cells and is downregulated by lymphodepleting drugs. Blood. 2015; 125:3905-3916. [PubMed: 25940712]

23. Li X, Ye F, Chen H, et al. Human ovarian carcinoma cells generate CD4(+)CD25(+) regulatory T cells from peripheral CD4(+)CD25(-) T cells through secreting TGF-beta. Cancer Lett. 2007; 253:144-153. [PubMed: 17353088]

24. Chen LL, Ye F, Lü WG, et al. Evaluation of immune inhibitory cytokine profles in epithelial ovarian carcinoma. J Obstet Gynaecol Res. 2009; 35:212-218. [PubMed: 19335794]

25. Zhao X, Ye F, Chen L, et al. Human epithelial ovarian carcinoma cell-derived cytokines cooperatively induce activated $\mathrm{CD} 4^{+} \mathrm{CD} 25^{-} \mathrm{CD} 45 \mathrm{RA}^{+}$naïve $\mathrm{T}$ cells to express forkhead box protein 3 and exhibit suppressive ability in vitro. Cancer Sci. 2009; 100:2143-2151. [PubMed: 19673890]

26. Brown CE, Badie B, Barish ME, et al. Bioactivity and safety of IL13Ra2-redirected chimeric antigen receptor $\mathrm{CD} 8^{+} \mathrm{T}$ cells in patients with recurrent glioblastoma. Clin Cancer Res. 2015; 21:4062-4072. [PubMed: 26059190]

27. Louis CU, Savoldo B, Doffi G, et al. Antitumor activity and long-term fate of chimeric antigen receptor-positive T cells in patients with neuroblastoma. Blood. 2011; 118:6050-6056. [PubMed: 21984804]

28. Park JR, Digiusto DL, Slovak M, et al. Adoptive transfer of chimeric antigen receptor re-directed cytolytic T lymphocyte clones in patients with neuroblastoma. Mol Ther. 2007; 15:825-833. [PubMed: 17299405]

29. Feng K, Guo Y, Dai H, et al. Chimeric antigen receptor-modifed T cells for the immunotherapy of patients with EGFR-expressing advanced relapsed/refractory non-small cell lung cancer. Sci China Life Sci. 2016; 59:468-479. [PubMed: 26968708]

30. Slovin SF, Wang X, Hullings M, et al. Chimeric antigen receptor (CAR+) modifed T cells targeting prostate specifc membrane antigen (PSMA) in patients (pts) with castrate metastatic prostate cancer (CMPC). J Clin Oncol. 2013; 31(suppl) abstrTPS3115.

31. Lamers CH, Sleijfer S, Vulto AG, et al. Treatment of metastatic renal cell carcinoma with autologous T-lymphocytes genetically retargeted against carbonic anhydrase IX: frst clinical experience. J Clin Oncol. 2006; 24:e20-e22. [PubMed: 16648493]

32. Kershaw MH, Westwood JA, Parker LL, et al. A phase I study on adoptive immunotherapy using gene-modifed T cells for ovarian cancer. Clin Cancer Res. 2006; 12:6106-6115. [PubMed: 17062687] 
33. Ahmed N, Brawley VS, Hegde M, et al. Human epidermal growth factor receptor 2 (HER2) specifc chimeric antigen receptor-modifed T cells for the immunotherapy of HER2-positive sarcoma. J Clin Oncol. 2015; 33:1688-1696. [PubMed: 25800760]

34. Brown CE, Warden CD, Starr R, et al. Glioma IL13Ra2 is associated with mesenchymal signature gene expression and poor patient prognosis. PLoS One. 2013; 8:e77769. [PubMed: 24204956]

35. Kahlon KS, Brown C, Cooper LJ, et al. Specifc recognition and killing of glioblastoma multiforme by interleukin 13-zetakine redirected cytolytic T cells. Cancer Res. 2004; 64:9160-9166. [PubMed: 15604287]

36. Brown CE, Starr R, Aguilar B, et al. Stem-like tumor-initiating cells isolated from IL13Ra2 expressing gliomas are targeted and killed by IL13-zetakine-redirected T Cells. Clin Cancer Res. 2012; 18:2199-2209. [PubMed: 22407828]

37. Hombach A, Wieczarkowiecz A, Marquardt T, et al. Tumor-specific T cell activation by recombinant immunoreceptors: CD3 zeta signaling and CD28 costimulation are simultaneously required for efficient IL-2 secretion and can be integrated into one combined CD28/CD3 zeta signaling receptor molecule. J Immunol. 2001; 167:6123-6131. [PubMed: 11714771]

38. Brown CE, Alizadeh D, Starr R, et al. Regression of glioblastoma after chimeric antigen receptor T-cell therapy. N Engl J Med. 2016; 375:2561-2569. [PubMed: 28029927]

39. Morgan RA, Johnson LA, Davis JL, et al. Recognition of glioma stem cells by genetically modified T cells targeting EGFRvIII and development of adoptive cell therapy for glioma. Hum Gene Ther. 2012; 23:1043-1053. [PubMed: 22780919]

40. Ohno M, Ohkuri T, Kosaka A, et al. Expression of miR-17-92 enhances anti-tumor activity of Tcells transduced with the anti-EGFRvIII chimeric antigen receptor in mice bearing human GBM xenografts. J Immunother Cancer. 2013; 1:21. [PubMed: 24829757]

41. Choi BD, Suryadevara CM, Gedeon PC, et al. Intracerebral delivery of a third generation EGFRvIII-specific chimeric antigen receptor is efficacious against human glioma. J Clin Neurosci. 2014; 21:189-190. [PubMed: 24054399]

42. Schulz G, Cheresh DA, Varki NM, et al. Detection of ganglioside GD2 in tumor tissues and sera of neuroblastoma patients. Cancer Res. 1984; 44:5914-5920. [PubMed: 6498849]

43. Rossig C, Bollard CM, Nuchtern JG, et al. Epstein-Barr virus-specific human T lymphocytes expressing antitumor chimeric T-cell receptors: potential for improved immunotherapy. Blood. 2002; 99:2009-2016. [PubMed: 11877273]

44. Gavert N, Conacci-Sorrell M, Gast D, et al. L1, a novel target of beta-catenin signaling, transforms cells and is expressed at the invasive front of colon cancers. J Cell Biol. 2005; 168:633-642. [PubMed: 15716380]

45. Gonzalez S, Naranjo A, Serrano LM, et al. Genetic engineering of cytolytic T lymphocytes for adoptive T-cell therapy of neuroblastoma. J Gene Med. 2004; 6:704-711. [PubMed: 15170741]

46. Turtle CJ, Hanafi LA, Berger C, et al. CD19 CAR-T cells of defined CD4 ${ }^{+}: \mathrm{CD}^{+}$composition in adult B cell ALL patients. J Clin Invest. 2016; 126:2123-2138. [PubMed: 27111235]

47. Craddock JA, Lu A, Bear A, et al. Enhanced tumor trafficking of GD2 chimeric antigen receptor T cells by expression of the chemokine receptor CCR2b. J Immunother. 2010; 33:780-788. [PubMed: 20842059]

48. Calcinotto A, Grioni M, Jachetti E, et al. Targeting TNF-a to neoangiogenic vessels enhances lymphocyte infiltration in tumors and increases the therapeutic potential of immunotherapy. $\mathrm{J}$ Immunol. 2012; 188:2687-2694. [PubMed: 22323546]

49. Kuramitsu S, Ohno M, Ohka F, et al. Lenalidomide enhances the function of chimeric antigen receptor T cells against the epidermal growth factor receptor variant III by enhancing immune synapses. Cancer Gene Ther. 2015; 22:487-495. [PubMed: 26450624]

50. Hynes NE, MacDonald G. ErbB receptors and signaling pathways in cancer. Curr Opin Cell Biol. 2009; 21:177-184. [PubMed: 19208461]

51. Rogers SJ, Harrington KJ, Rhys-Evans P, et al. Biological significance of c-erb B family oncogenes in head and neck cancer. Cancer Metastasis Rev. 2005; 24:47-69. [PubMed: 15785872]

52. Foley J, Nickerson NK, Nam S, et al. EGFR signaling in breast cancer: bad to the bone. Semin Cell Dev Biol. 2010; 21:951-960. [PubMed: 20813200] 
53. Hirsch FR, Varella-Garcia M, Cappuzzo F. Predictive value of EGFR and HER2 overexpression in advanced non-small cell lung cancer. Oncogene. 2009; 28(Suppl 1):S32-S37. [PubMed: 19680294]

54. Holbro T, Civenni G, Hynes NE. The ErbB receptors and their role in cancer progression. Exp Cell Res. 2003; 284:99-110. [PubMed: 12648469]

55. Olayioye MA, Neve RM, Lane HA, et al. The ErbB signaling network: receptor heterodimerization in development and cancer. EMBO J. 2000; 19:3159-3167. [PubMed: 10880430]

56. Davies DM, Foster J, Van Der Stegen SJ, et al. Flexible targeting of ErbB dimers that drive tumorigenesis by using genetically engineered T cells. Mol Med. 2012; 18:565-576. [PubMed: 22354215]

57. van der Stegen SJ, Davies DM, Wilkie S, et al. Preclinical in vivo modeling of cytokine release syndrome induced by ErbB-retargeted human T cells: identifying a window of therapeutic opportunity? J Immunol. 2013; 191:4589-4598. [PubMed: 24062490]

58. van Schalkwyk MC, Papa SE, Jeannon JP, et al. Design of a phase I clinical trial to evaluate intratumoral delivery of $E r b B$-targeted chimeric antigen receptor T-cells in locally advanced or recurrent head and neck cancer. Hum Gene Ther Clin Dev. 2013; 24:134-142. [PubMed: 24099518]

59. Ferris RL. Immunology and immunotherapy of head and neck cancer. J Clin Oncol. 2015; 33:3293-3304. [PubMed: 26351330]

60. Albers AE, Ferris RL, Kim GG, et al. Immune responses to p53 in patients with cancer: enrichment in tetramer-positive p53 peptide-specific $\mathrm{T}$ cells and regulatory $\mathrm{T}$ cells at tumor sites. Cancer Immunol Immunother. 2005; 54:1072-1081. [PubMed: 15959774]

61. Witton CJ, Reeves JR, Going JJ, et al. Expression of the HER1-4 family of receptor tyrosine kinases in breast cancer. J Pathol. 2003; 200:290-297. [PubMed: 12845624]

62. Globerson-Levin A, Waks T, Eshhar Z. Elimination of progressive mammary cancer by repeated administrations of chimeric antigen receptor-modified T cells. Mol Ther. 2014; 22:1029-1038. [PubMed: 24572294]

63. Morello A, Sadelain M, Adusumilli PS. Mesothelin-targeted CARs: driving T cells to solid tumors. Cancer Discov. 2016; 6:133-146. [PubMed: 26503962]

64. Li YR, Xian RR, Ziober A, et al. Mesothelin expression is associated with poor outcomes in breast cancer. Breast Cancer Res Treat. 2014; 147:675-684. [PubMed: 25193277]

65. Tchou J, Wang LC, Selven B, et al. Mesothelin, a novel immunotherapy target for triple negative breast cancer. Breast Cancer Res Treat. 2012; 133:799-804. [PubMed: 22418702]

66. Ruella M, Barrett DM, Kenderian SS, et al. Dual CD19 and CD123 targeting prevents antigen-loss relapses after CD19-directed immunotherapies. J Clin Invest. 2016; 126:3814-3826. [PubMed: 27571406]

67. Pegram HJ, Lee JC, Hayman EG, et al. Tumor-targeted T cells modified to secrete IL-12 eradicate systemic tumors without need for prior conditioning. Blood. 2012; 119:4133-4141. [PubMed: 22354001]

68. Zhao Z, Condomines M, van der Stegen SJ, et al. Structural design of engineered costimulation determines tumor rejection kinetics and persistence of CAR T cells. Cancer Cell. 2015; 28:415428. [PubMed: 26461090]

69. Kachala SS, Bograd AJ, Villena-Vargas J, et al. Mesothelin overexpression is a marker of tumor aggressiveness and is associated with reduced recurrence-free and overall survival in early-stage lung adenocarcinoma. Clin Cancer Res. 2014; 20:1020-1028. [PubMed: 24334761]

70. Grunnet M, Sorensen JB. Carcinoembryonic antigen (CEA) as tumor marker in lung cancer. Lung Cancer. 2012; 76:138-143. [PubMed: 22153832]

71. Carpenito C, Milone MC, Hassan R, et al. Control of large, established tumor xenografts with genetically retargeted human T cells containing CD28 and CD137 domains. Proc Natl Acad Sci USA. 2009; 106:3360-3365. [PubMed: 19211796]

72. Lanitis E, Poussin M, Hagemann IS, et al. Redirected antitumor activity of primary human lymphocytes transduced with a fully human anti-mesothelin chimeric receptor. Mol Ther. 2012; 20:633-643. [PubMed: 22127019] 
73. Adusumilli PS, Cherkassky L, Villena-Vargas J, et al. Regional delivery of mesothelin-targeted CAR T cell therapy generates potent and long-lasting CD4-dependent tumor immunity. Sci Transl Med. 2014; 6:261ra151.

74. Emtage PC, Lo AS, Gomes EM, et al. Second-generation anti-carcinoembryonic antigen designer $\mathrm{T}$ cells resist activation-induced cell death, proliferate on tumor contact, secrete cytokines, and exhibit superior antitumor activity in vivo: a preclinical evaluation. Clin Cancer Res. 2008; 14:8112-8122. [PubMed: 19088026]

75. Maus MV, Haas AR, Beatty GL, et al. T cells expressing chimeric antigen receptors can cause anaphylaxis in humans. Cancer Immunol Res. 2013; 1:26-31.

76. Konishi J, Yamazaki K, Azuma M, et al. B7-H1 expression on non-small cell lung cancer cells and its relationship with tumor-infiltrating lymphocytes and their PD-1 expression. Clin Cancer Res. 2004; 10:5094-5100. [PubMed: 15297412]

77. Mansfield AS, Roden AC, Peikert T, et al. B7-H1 expression in malignant pleural mesothelioma is associated with sarcomatoid histology and poor prognosis. J Thorac Oncol. 2014; 9:1036-1040. [PubMed: 24926549]

78. Suzuki Y, Suda T, Furuhashi K, et al. Increased serum kynurenine/tryptophan ratio correlates with disease progression in lung cancer. Lung Cancer. 2010; 67:361-365. [PubMed: 19487045]

79. Cherkassky L, Morello A, Villena-Vargas J, et al. Human CAR T cells with cell-intrinsic PD-1 checkpoint blockade resist tumor-mediated inhibition. J Clin Invest. 2016; 126:3130-3144. [PubMed: 27454297]

80. Barber A, Zhang T, DeMars LR, et al. Chimeric NKG2D receptor-bearing T cells as immunotherapy for ovarian cancer. Cancer Res. 2007; 67:5003-5008. [PubMed: 17510432]

81. Yoon SH, Lee JM, Cho HI, et al. Adoptive immunotherapy using human peripheral blood lymphocytes transferred with RNA encoding Her-2/neu-specific chimeric immune receptor in ovarian cancer xenograft; model. Cancer Gene Ther. 2009; 16:489-497. [PubMed: 19096447]

82. Zhang S, Zhang HS, Cordon-Cardo C, et al. Selection of tumor antigens as targets for immune attack using immunohistochemistry: II. Blood group-related antigens. Int J Cancer. 1997; 73:5056. [PubMed: 9334809]

83. Miyake M, Taki T, Hitomi S, et al. Correlation of expression of H/Le(y)/Le(b) antigens with survival in patients with carcinoma of the lung. N Engl J Med. 1992; 327:14-18. [PubMed: 1317941]

84. Sakamoto J, Furukawa K, Cordon-Cardo C, et al. Expression of Lewis-a, Lewis-b, X, and Y blood group antigens in human colonic tumors and normal tissue and in human tumor-derived cell lines. Cancer Res. 1986; 46:1553-1561. [PubMed: 3510728]

85. Westwood JA, Smyth MJ, Teng MW, et al. Adoptive transfer of T cells modified with a humanized chimeric receptor gene inhibits growth of Lewis-Y-expressing tumors in mice. Proc Natl Acad Sci USA. 2005; 102:19051-19056. [PubMed: 16365285]

86. Dharma Rao T, Park KJ, Smith-Jones P, et al. Novel monoclonal antibodies against the proximal (carboxy-terminal) portions of MUC16. Appl Immunohistochem Mol Morphol. 2010; 18:462-472. [PubMed: 20453816]

87. Koneru M, Purdon TJ, Spriggs D, et al. IL-12 secreting tumor-targeted chimeric antigen receptor T cells eradicate ovarian tumors in vivo. Onco Immunology. 2015; 4:e994446.

88. Chang K, Pastan I. Molecular cloning of mesothelin, a differentiation antigen present on mesothelium, mesotheliomas, and ovarian cancers. Proc Natl Acad Sci USA. 1996; 93:136-140. [PubMed: 8552591]

89. Elnakat H, Ratnam M. Distribution, functionality and gene regulation of folate receptor isoforms: implications in targeted therapy. Adv Drug Deliv Rev. 2004; 56:1067-1084. [PubMed: 15094207]

90. Toffoli G, Cernigoi C, Russo A, et al. Overexpression of folate binding protein in ovarian cancers. Int J Cancer. 1997; 74:193-198. [PubMed: 9133455]

91. Toffoli G, Russo A, Gallo A, et al. Expression of folate binding protein as a prognostic factor for response to platinum-containing chemotherapy and survival in human ovarian cancer. Int $\mathrm{J}$ Cancer. 1998; 79:121-126. [PubMed: 9583724]

92. Hwu P, Yang JC, Cowherd R, et al. In vivo antitumor activity of T cells redirected with chimeric antibody/T-cell receptor genes. Cancer Res. 1995; 55:3369-3373. [PubMed: 7614473] 
93. Kim S, Kim B, Song YS. Ascites modulates cancer cell behavior, contributing to tumor heterogeneity in ovarian cancer. Cancer Sci. 2016; 107:1173-1178. [PubMed: 27297561]

94. Zhao J, Zhao J, Perlman S. Differential effects of IL-12 on Tregs and non-Treg T cells: roles of IFN- $\gamma$, IL-2 and IL-2R. PLoS One. 2012; 7:e46241. [PubMed: 23029447]

95. Kerkar SP, Goldszmid RS, Muranski P, et al. IL-12 triggers a programmatic change in dysfunctional myeloid-derived cells within mouse tumors. J Clin Invest. 2011; 121:4746-4757. [PubMed: 22056381]

96. Oelkrug C, Ramage JM. Enhancement of T cell recruitment and infiltration into tumours. Clin Exp Immunol. 2014; 178:1-8.

97. Esposito A, Criscitiello C, Curigliano G. Immune checkpoint inhibitors with radiotherapy and locoregional treatment: synergism and potential clinical implications. Curr Opin Oncol. 2015; 27:445-451. [PubMed: 26447875]

98. Tricoli JV, Schoenfeldt M, Conley BA. Detection of prostate cancer and predicting progression: current and future diagnostic markers. Clin Cancer Res. 2004; 10:3943-3953. [PubMed: 15217924]

99. Leek J, Lench N, Maraj B, et al. Prostate-specific membrane antigen: evidence for the existence of a second related human gene. Br J Cancer. 1995; 72:583-588. [PubMed: 7669565]

100. DeMarzo AM, Nelson WG, Isaacs WB, et al. Pathological and molecular aspects of prostate cancer. Lancet. 2003; 361:955-964. [PubMed: 12648986]

101. Hillerdal V, Ramachandran M, Leja J, et al. Systemic treatment with CAR-engineered T cells against PSCA delays subcutaneous tumor growth and prolongs survival of mice. BMC Cancer. 2014; 14:30. [PubMed: 24438073]

102. Junghans RP, Ma Q, Rathore R, et al. Phase I trial of anti-PSMA designer CAR T Cells in prostate cancer: possible role for interacting interleukin $2 \mathrm{~T}$ cell pharmacodynamics as a determinant of clinical response. Prostate. 2016; 76:1257-1270. [PubMed: 27324746]

103. Qian BZ, Pollard JW. Macrophage diversity enhances tumor progression and metastasis. Cell. 2010; 141:39-51. [PubMed: 20371344]

104. Ostrand-Rosenberg S, Sinha P. Myeloid-derived suppressor cells: linking inflammation and cancer. J Immunol. 2009; 182:4499-4506. [PubMed: 19342621]

105. Halin S, Rudolfsson SH, Van Rooijen N, et al. Extratumoral macrophages promote tumor and vascular growth in an orthotopic rat prostate tumor model. Neoplasia. 2009; 11:177-186. [PubMed: 19177202]

106. Zhu P, Baek SH, Bourk EM, et al. Macrophage/cancer cell Interactions mediate hormone resistance by a nuclear receptor derepression pathway. Cell. 2006; 124:615-629. [PubMed: 16469706]

107. TafreshI NK, Lloyd MC, BuI MM, et al. Carbonic anhydrase IX as an Imaging and therapeutic target for tumors and metastases. Subcell Biochem. 2014; 75:221-254. [PubMed: 24146382]

108. Pastoreková S, Parkkila S, Parkkila AK, et al. Carbonic anhydrase IX, MN/CA IX: analysis of stomach complementary DNA sequence and expression in human and rat alimentary tracts. Gastroenterology. 1997; 112:398-408. [PubMed: 9024293]

109. Ivanov S, Liao SY, Ivanova A, et al. Expression of hypoxia-inducible cell-surface transmembrane carbonic anhydrases in human cancer. Am J Pathol. 2001; 158:905-919. [PubMed: 11238039]

110. Weijtens ME, Willemsen RA, Valerio D, et al. Single chain Ig/gamma gene-redirected human T lymphocytes produce cytokines, specifically lyse tumor cells, and recycle lytic capacity. $\mathrm{J}$ Immunol. 1996; 157:836-843. [PubMed: 8752936]

111. Walter S, Weinschenk T, Stenzl A, et al. Multipeptide immune response to cancer vaccine IMA901 after single-dose cyclophosphamide associates with longer patient survival. Nat Med. 2012; 18:1254-1261. [PubMed: 22842478]

112. Finke JH, Rayman PA, Ko JS, et al. Modification of the tumor microenvironment as a novel target of renal cell carcinoma therapeutics. Cancer J. 2013; 19:353-364. [PubMed: 23867518]

113. Rodriguez PC, Zea AH, Culotta KS, et al. Regulation of T cell receptor CD3zeta chain expression by L-arginine. J Biol Chem. 2002; 277:21123-21129. [PubMed: 11950832] 
114. Cesana GC, DeRaffele G, Cohen S, et al. Characterization of CD4*CD25* regulatory T cells in patients treated with high-dose interleukin-2 for metastatic melanoma or renal cell carcinoma. J Clin Oncol. 2006; 24:1169-1177. [PubMed: 16505437]

115. Siddiqui SA, Frigola X, Bonne-Annee S, et al. Tumor-infiltrating Foxp3-CD4 ${ }^{+} \mathrm{CD} 25^{+} \mathrm{T}$ cells predict poor survival in renal cell carcinoma. Clin Cancer Res. 2007; 13:2075-2081. [PubMed: 17404089]

116. Ko JS, Zea AH, Rini BI, et al. Sunitinib mediates reversal of myeloid-derived suppressor cell accumulation in renal cell carcinoma patients. Clin Cancer Res. 2009; 15:2148-2157. [PubMed: 19276286]

117. Finke JH, Rini B, Ireland J, et al. Sunitinib reverses type-1 immune suppression and decreases Tregulatory cells in renal cell carcinoma patients. Clin Cancer Res. 2008; 14:6674-6682. [PubMed: 18927310]

118. Tracz A, Mastri M, Lee CR, et al. Modeling spontaneous metastatic renal cell carcinoma (mRCC) in mice following nephrectomy. J Vis Exp. 2014; (86):51485.

119. Ahmed N, Salsman VS, Yvon E, et al. Immunotherapy for osteosarcoma: genetic modification of T cells overcomes low levels of tumor antigen expression. Mol Ther. 2009; 17:1779-1787. [PubMed: 19532139]

120. Lehner M, Götz G, Proff J, et al. RedirectingT cells to Ewing's sarcoma family of tumors by a chimeric NKG2D receptor expressed by lentiviral transduction or mRNA transfection. PLoS One. 2012; 7:e31210. [PubMed: 22355347]

121. Huang G, Yu L, Cooper LJ, et al. Genetically modified T cells targeting interleukin-11 receptor a-chain kill human osteosarcoma cells and induce the regression of established osteosarcoma lung metastases. Cancer Res. 2012; 72:271-281. [PubMed: 22075555]

122. Lewis VO, Ozawa MG, Deavers MT, et al. The interleukin-11 receptor alpha as a candidate ligand-directed target in osteosarcoma: consistent data from cell lines, orthotopic models, and human tumor samples. Cancer Res. 2009; 69:1995-1999. [PubMed: 19244100]

123. Campbell CL, Jiang Z, Savarese DM, et al. Increased expression of the interleukin-11 receptor and evidence of STAT3 activation in prostate carcinoma. Am J Pathol. 2001; 158:25-32. [PubMed: 11141475]

124. Hanavadi S, Martin TA, Watkins G, et al. Expression of interleukin 11 and its receptor and their prognostic value in human breast cancer. Ann Surg Oncol. 2006; 13:802-808. [PubMed: 16614887]

125. Schwertschlag US, Trepicchio WL, Dykstra KH, et al. Hematopoietic, immunomodulatory and epithelial effects of interleukin-11. Leukemia. 1999; 13:1307-1315. [PubMed: 10482979]

126. Teramura M, Kobayashi S, Yoshinaga K, et al. Effect of interleukin 11 on normal and pathological thrombopoiesis. Cancer Chemother Pharmacol. 1996; 38(Suppl):S99-S102. [PubMed: 8765427]

127. Engellau J, Bendahl PO, Persson A, et al. Improved prognostication in soft tissue sarcoma: independent information from vascular invasion, necrosis, growth pattern, and immunostaining using whole-tumor sections and tissue microarrays. Hum Pathol. 2005; 36:994-1002. [PubMed: 16153463]

128. Castelli C, Rivoltini L, Rodolfo M, et al. Modulation of the myeloid compartment of the immune system by angiogenic- and kinase inhibitor-targeted anti-cancer therapies. Cancer Immunol Immunother. 2015; 64:83-89. [PubMed: 24993564]

129. Germano G, Frapolli R, Belgiovine C, et al. Role of macrophage targeting in the antitumor activity of trabectedin. Cancer Cell. 2013; 23:249-262. [PubMed: 23410977] 


\section{KEY POINTS}

- $\quad$ CAR T-cell therapy has emerged as a promising immunotherapeutic approach for solid tumor malignancies and several promising candidates are in earlyphase clinical trials.

- Despite tumor and antigen heterogeneity, several TAAs such as MUC-16, GD2, EGFRIII, mesothelin and PSMA have been identified as targets for CAR T-cell therapy.

- Clinical responses have been reported in a small subset of solid tumor malignancies; however, increased response rates and responses across a broader range of tumor types are required.

- $\quad$ CAR T-cell efficacy is limited by various intrinsic and extrinsic factors, including poor trafficking to tumor site and an immunosuppressive tumor microenvironment.

- $\quad$ Further genetic engineering to optimize CAR design (armored CAR T cells) or combinatorial approaches with cytotoxic, targeted therapy, and immunomodulatory agents are currently under investigation. 


\section{ᄅ⿳亠口冋亍}

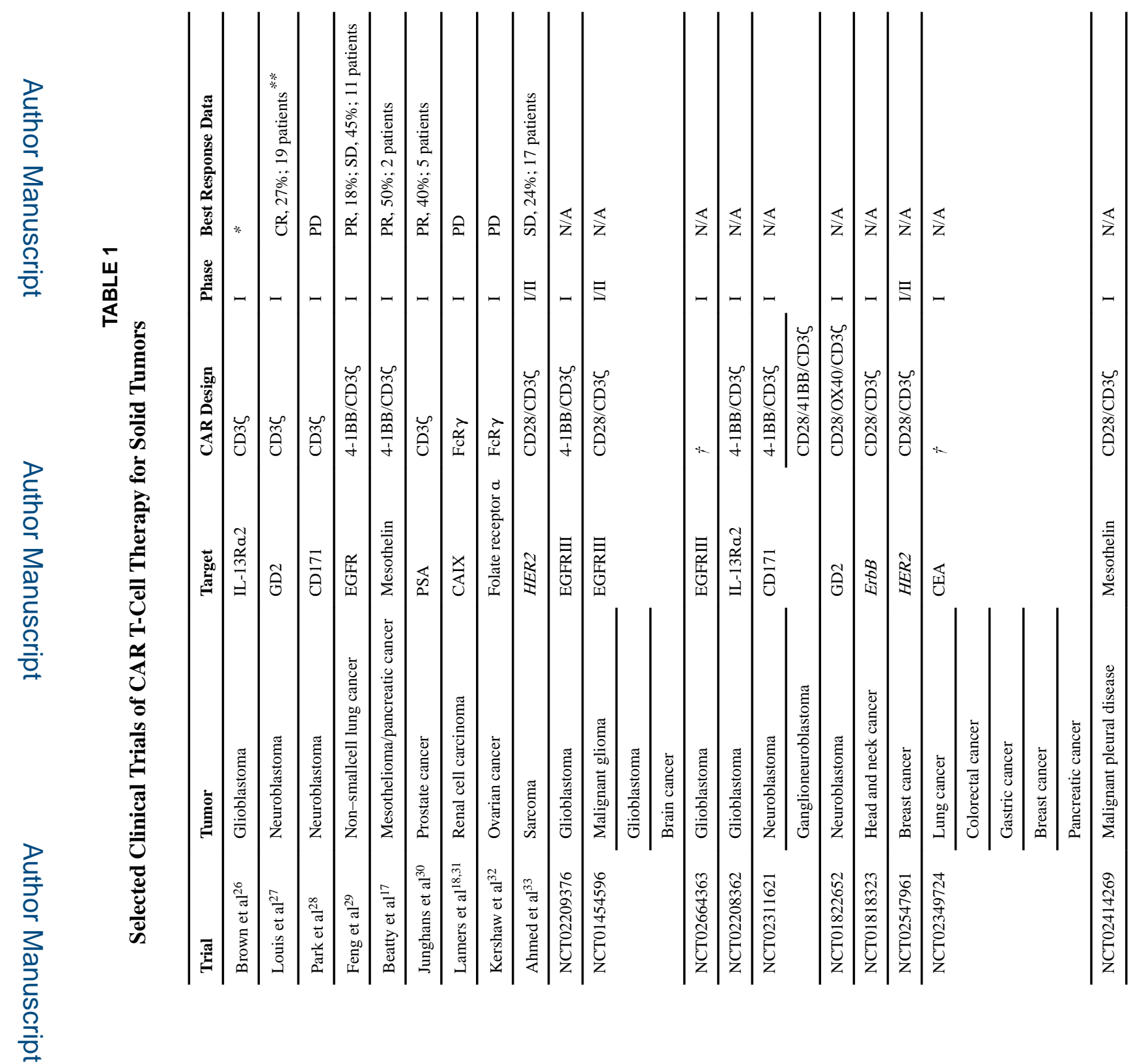




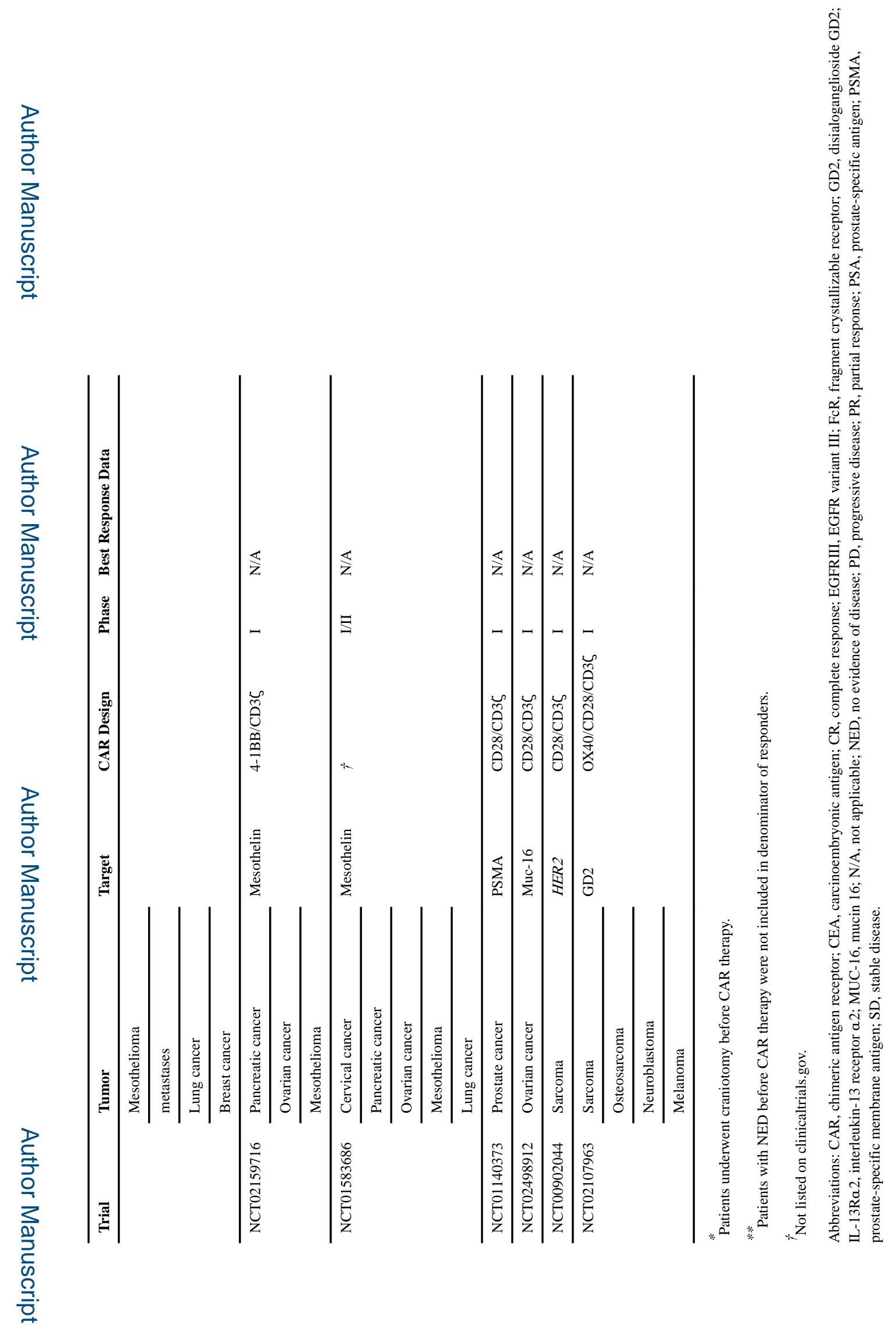

Am Soc Clin Oncol Educ Book. Author manuscript; available in PMC 2017 August 09. 